\title{
A família como um dos fatores de risco e de proteção nas situações de gestação e maternidade na adolescência
}

\section{The family as a risk factor and protection in situations of pregnancy and teenage motherhood}

\author{
Naiana Dapieve Patias* \\ Universidade Federal do Rio Grande do Sul - UFRGS, Porto Alegre, Rio Grande do \\ Sul, Brasil.
}

\section{Marília Reginato Gabriel**}

Universidade Federal do Rio Grande do Sul - UFRGS, Porto Alegre, Rio Grande do Sul, Brasil.

\section{Ana Cristina Garcia Dias***}

Universidade Federal de Santa Maria - UFSM, Santa Maria, Rio Grande do Sul, Brasil

\begin{abstract}
RESUMO
O presente trabalho buscou compreender como o contexto familiar pode servir como fator de risco e de proteção na situação da gestação e maternidade na adolescência. Realizou-se uma revisão sistemática da literatura nos portais Scielo e Pepsic, com os descritores família, adolescência, gravidez, gestação, maternidade, sexualidade, vulnerabilidade, risco e proteção, no período de 2000 a 2010. Para análise do material, utilizou-se uma análise temática de conteúdo. Os resultados sugerem que, dentre os fatores de risco estão: dificuldades no relacionamento familiar, repetição da história familiar de gestação, a ocorrência de gestações sucessivas durante a adolescência, falta ou inadequação da orientação sexual, quantidade de apoio familiar recebido, situações de violência, crenças e valores sobre parentalidade, abuso de drogas. Já entre os fatores de proteção encontra-se: relacionamento familiar satisfatório, apoio recebido da família e impacto positivo advindo da gravidez adolescente. Esses resultados são discutidos a partir da concepção processual de risco/proteção. Palavras chave: Adolescência, Gestação, Maternidade, Risco e proteção, Família.
\end{abstract}

\section{ABSTRACT}

This study sought to understand the family context, both as risk and protective factor in the situation of teenage pregnancy and motherhood. We conducted a systematic review of the literature on search engines Scielo and Pepsic, with descriptors family, adolescence, pregnancy, pregnancy, maternity, sexuality, vulnerability, risk and protection in the period 2000 to 2010. To analyze the material we used a thematic analysis. The results suggest that among the risk factors are: difficulties in family relationships, 
family history of repeated pregnancy, the occurrence of subsequent pregnancies during adolescence, lack or inadequacy of sexual orientation, amount of family support received, violent situations, beliefs and values about parenting, drug abuse. Among the protective factors found: good family relationships, support from family and positive impact arising from the pregnancy adolescent. These results are discussed from the procedural conception of risk / protection.

Key words: Adolescence, Pregnancy, Maternity, Risk and protection, Family.

\section{I ntrodução}

A adolescência caracteriza-se por ser um período de vida, situado entre a infância e a vida adulta, que possui características específicas. Neste período, o adolescente encontra-se frente a uma série de tarefas desenvolvimentais: a separação progressiva dos pais, a construção da sua identidade, o luto pelo corpo infantil, a busca de novas identificações para além da família, entre outras. Nesse cenário podem surgir dificuldades tanto para o adolescente quanto para seus pais e pessoas de seus contextos de desenvolvimento próximo (BERTHOUD, 2002; KNOBEL, 1981).

Neste sentido, a fase do ciclo vital suscita geralmente readaptações na dinâmica familiar, uma vez que as antigas crenças e práticas não fazem o mesmo efeito sobre este sistema. As novas demandas do filho adolescente e os riscos aos quais o adolescente pode estar submetido trazem preocupações e dificuldades para os pais, principalmente na resolução de conflitos e na orientação em assuntos pouco falados pela própria família associado a alguns comportamentos de risco na adolescência (por exemplo, exercício desprotegido da sexualidade). Os pais, numa tentativa de atenuar os conflitos, tendem a continuar a empregar estratégias que costumavam funcionar na infância do filho, tentando "puxar as rédeas" do adolescente ou retraindo-se emocionalmente para evitar novos conflitos (PRETO, 1995). Assim, observa-se que os pais podem sentir diversas dificuldades em como lidar com os filhos e em como orientá-los nessa nova fase do desenvolvimento, que lhe impõem novas tarefas como pais.

De fato, a adolescência é um momento de transformações não só para o adolescente, mas também para a família que deverá passar por mudanças para adaptar-se a esse novo momento do ciclo vital de seus membros. Este processo perpassa a fronteira da experiência individual do jovem e afeta todo o sistema ${ }^{1}$ que também adolesce durante o período (BERTHOUD, 2002).

A família pode ser considerada o sistema mais importante na vida dos indivíduos (CERVENY; BERTHOUD, 2002). Para Shaffer (2005), a família possui o papel de ser fonte de segurança, afeto, proteção e 
bem-estar, funções as quais nem sempre consegue cumprir com todas as crianças, em todas as situações. De fato, destaca-se que ela também pode se constituir em um fator de risco para o desenvolvimento de crianças e adolescentes (SCHENKER; MINAYO, 2005). Quando a família não cumpre o seu papel de proteção, cuidando dos seus filhos, dando amor e limites, ela pode servir como um fator de risco para o desenvolvimento dos mesmos (WEBER, 2007).

O presente trabalho buscou compreender como o contexto familiar pode servir tanto como fator de risco ou de proteção na situação de gestação e maternidade adolescente. Propõe-se realizar uma revisão sistemática da literatura, da última década, em dois portais de periódicos, para compreender como a família, um dos principais contextos de desenvolvimento, pode influenciar o desenvolvimento dos fenômenos da gestação e maternidade ${ }^{2}$ neste período da vida. Parte-se das concepções que tanto a gestação e maternidade adolescente como as relações familiares durante a adolescência são fenômenos complexos e multifatoriais (TEIXEIRA; DIAS, 2010; LEVANDOWSKI; PICCININI; LOPES, 2008). Desta forma, considera-se importante entender o que está sendo produzido sobre o tema. A literatura indica que a família tanto pode se constituir em um fator de proteção e apoio para as jovens e seus bebês, como um fator de risco, que contribui para a ocorrência da gestação e para a obtenção de piores resultados, em termos de desenvolvimento das adolescentes e de seus bebês.

A escolha de analisar a produção sobre família deve-se tanto ao reconhecimento de sua importância como contexto de desenvolvimento dos indivíduos, quanto pelo fato de que durante a adolescência, os jovens são particularmente sensíveis à influência de fatores ambientais, devido a características desenvolvimentais (VILLELA; DORETO, 2006). A situação de gestação e maternidade adolescente foi escolhida, pois compreende-se que esses fenômenos, ao serem vivenciados durante a adolescência trazem demandas especificas aos jovens e suas famílias, gerando dificuldades adicionais (HOGA ET AL. 2009; LEVANDOWSKI; PICCININI; LOPES, 2008). Algumas características como afeto, limite e continência experienciados de maneira significativa no contexto familiar servem como fatores de proteção para os riscos aos quais o adolescente está exposto; por outro lado, relações familiares conturbadas e difíceis (abusadoras, negligentes) podem servir como fator de risco para a emergência de situações inesperadas e mesmo desadaptativas, como a adoção de comportamentos sexuais de risco, e consequente, gestação/ maternidade adolescente (GODINHO; SHELP; PARADA; BERTONCELLO, 2000; LEVANDOWSKI; PICCININI; LOPES, 2008).

O presente artigo pretende analisar e aprofundar o conhecimento sobre a associação da família e gestação/maternidade na 
adolescência, a luz da literatura PSI, produzida no Brasil na última década.

Considera-se que os fatores de risco são condições ou variáveis que estão associadas a uma alta probabilidade de ocorrência de resultados negativos ou indesejáveis no desenvolvimento do adolescente que podem comprometer a saúde, bem-estar ou performance social do indivíduo (MORAIS, 2009). Cecconello, Antoni e Koller (2003) apontam que os fatores de risco podem estar presentes em características individuais (sexo, fatores genéticos, habilidades sociais, intelectuais e características psicológicas) e ambientais (baixo nível sócio-econômico, eventos de vida estressantes, características familiares e ausência de apoio social).

Por outro lado, os fatores de proteção são compreendidos como condições ou variáveis que diminuem os fatores de risco, isto é, modificam, melhoram ou alteram a resposta do indivíduo a ambientes hostis os quais predispõem as consequências mal adaptativas (HUTZ, 2002). Segundo Morais (2009), os fatores de proteção explicam como diferentes indivíduos, submetidos às mesmas condições adversas, alcançam resultados desenvolvimentais diferentes. Como exemplo de fatores protetivos, Hutz (2002) destaca características individuais da criança e do adolescente (auto-estima, autonomia) e características familiares, tais como a afetividade, ausência de negligência. Também o apoio institucional, tal como o proporcionado, em certas situações, pela escola é considerado fator de proteção.

No entanto, é importante considerar que, atualmente, os pesquisadores têm trabalhado com uma perspectiva processual dos fatores de risco e proteção. Isto quer dizer que os efeitos de um fator de risco ou de proteção não são estáticos ou fixos, mas sim dependem de outros aspectos, como a situação, as características do indivíduo e o momento do desenvolvimento (MORAIS; KOLLER, 2004; MORAIS, 2009; YUNES; SZYMANSKY, 2003).

De fato, Yunes, Miranda e Cuello (2004) destacam que diferentes indivíduos podem reagir de forma diferente ao mesmo fator de risco ou de proteção. O risco não pode ser caracterizado como um fato, e nem suas condições podem ser assumidas a priori, mas sim por um ou mais processos que englobam uma sequência de eventos que necessitam de investigação. Assim, risco é processo, e não um estado absoluto e estável (YUNES; SZYMANSKY, 2003). Os fatores de proteção também devem ser considerados em um contexto e em sua capacidade de mitigar o risco potencial de um evento estressor (MORAIS; KOLLER, 2004).

No que se refere às situações de gestação e a maternidade na adolescência, sabe-se que vários são os fatores que, juntos tornam os adolescentes mais vulneráveis a esses fenômenos. A família é apenas um dos fatores que pode servir de risco como também de proteção envolvidos no fenômeno. Nesse sentido, devem ser 
considerados outros fatores que podem potencializar os riscos ou aumentar as situações de proteção. Compreende-se que a análise mais detida em um fator pode ampliar o conhecimento sobre o tema, desde que não seja esquecido que os fenômenos analisados são complexos e multifatoriais (TEIXEIRA; DIAS, 2010).

\section{Método}

Este trabalho resulta de uma revisão sistemática da literatura dos anos 2000 a 2010 sobre a gestação e maternidade na adolescência, a partir de uma perspectiva de estudos que tratam do contexto familiar. Lopes e Fraccolli (2008) indicam que os estudos de revisão sistemática de literatura buscam utilizar procedimentos padronizados, com critérios passíveis de reprodução, para analisar e realizar uma síntese descritiva e crítica de estudos primários sobre um dado fenômeno.

Foram consultadas as bases de dados: www.scielo.br e www. pepsic.bvsalud.org, sendo utilizados os descritores: adolescência and gestação and família; adolescência and gravidez and família; adolescência and maternidade and família; adolescência and sexualidade and família; adolescência and família and vulnerabilidade; adolescência and família and risco e adolescência and família and proteção. Cabe destacar que os termos adolescência e família sempre tiveram presentes na busca, devido o objetivo do artigo ser em relação a essa etapa do desenvolvimento com foco no contexto familiar. Além disso, os outros termos diziam respeito ao tema gestação ou maternidade e fator de risco e proteção, cabendo a busca de aspectos relativos a esses assuntos.

Para avaliação dos artigos foi utilizada a metodologia proposta por Gil (2006). Para esse autor, a leitura dos trabalhos é composta por quatro etapas: leitura exploratória, seletiva, analítica e interpretativa. $\mathrm{Na}$ primeira etapa, procura-se entrar em contato com os textos em sua totalidade, para após realizar uma leitura aprofundada das partes que interessam ao trabalho (leitura seletiva). O próximo passo consiste em ordenar e sumariar as informações encontradas, identificando-se as ideias-chave dos textos e construindo sínteses (leitura analítica). Na última etapa, a leitura interpretativa, procurase estabelecer relações entre o conteúdo dos textos pesquisados, agrupando-os e assim conferindo um alcance mais amplo aos resultados obtidos com a leitura analítica.

$\mathrm{Na}$ etapa de identificação do corpus de análise e leitura exploratória dos artigos, foram encontrados noventa e nove artigos na base de dados Scielo (www.scielo.br) e sete na base de dados Pepsic (www.pepsic.bvsalud.org), totalizando cento e seis artigos. Deste total, dois foram excluídos por serem publicações anteriores ao ano 
2000, restando cento e quatro artigos. Destes artigos restantes, trinta e nove estavam duplicados, assim restaram sessenta e cinco artigos a serem analisados. Esses sessenta e cinco artigos foram submetidos a uma primeira análise (leitura seletiva), que buscou delimitar a amostra de artigos a serem lidos em sua íntegra, e que fariam parte do corpus de análise sistemática deste estudo. Para determinação desse corpus tomou-se por base a questão da análise dos fatores de risco e proteção no contexto familiar, na situação de gestação e maternidade na adolescência.

O critério de inclusão dos artigos para participação na amostra final do estudo então foram tratar do tema da adolescência associado, ao menos, a um dos seguintes termos: gestação ou maternidade, família, sexualidade, risco e proteção. Os critérios de exclusão foram: não atender ao critério de inclusão; o artigo se referir apenas à fase adulta OU apenas à fase infantil; ou então enfocar apenas aspectos orgânicos da gestação durante a adolescência. Nesta etapa de análise foram excluídos mais quarenta e seis artigos, desta forma a amostra final de artigos que tratavam do tema foco deste estudo foram dezenove. A seguir é apresentado um quadro com os artigos analisados, a partir de alguns indicadores escolhidos a priori para análise dos mesmos.

Quadro - Análise dos artigos sobre família, fatores de risco e proteção, gestação e maternidade na adolescência

\begin{tabular}{|c|c|c|c|c|c|}
\hline Autores (ano) & Participantes & I dade & $\begin{array}{l}\text { Desenh } \\
\text { o do } \\
\text { Estudo }\end{array}$ & I nstrumentos & $\begin{array}{c}\text { Tipo de análise } \\
\text { de dados }\end{array}$ \\
\hline $\begin{array}{l}\text { HOGA; BORGES; } \\
\text { REBERTE (2010) }\end{array}$ & $\begin{array}{c}19 \text { familiares de } \\
\text { adolescentes mães } \\
\text { (mãe, pai, irmãos), de } \\
\text { camadas populares }\end{array}$ & $\begin{array}{c}23 \text { a } 56 \\
\text { anos }\end{array}$ & $\begin{array}{l}\text { Qualitati } \\
\text { vo }\end{array}$ & $\begin{array}{l}\text { Genograma } \\
\text { familiar, } \\
\text { entrevista } \\
\text { aberta. }\end{array}$ & $\begin{array}{c}\text { Análise da } \\
\text { narrativa }\end{array}$ \\
\hline $\begin{array}{c}\text { PERSONA; } \\
\text { SHIMO; TARALLO } \\
(2004)\end{array}$ & $\begin{array}{c}18 \text { adolescentes } \\
\text { grávidas, de camadas } \\
\text { populares }\end{array}$ & $\begin{array}{l}11 \text { a } 17 \\
\text { anos }\end{array}$ & $\begin{array}{l}\text { Quantita } \\
\text { tivo }\end{array}$ & $\begin{array}{l}\text { Prontuário } \\
\text { médico e } \\
\text { entrevista. }\end{array}$ & $\begin{array}{c}\text { Análise } \\
\text { quantitativa } \\
\text { pelo programa } \\
\text { Epi info } 2000\end{array}$ \\
\hline $\begin{array}{l}\text { SOARES et al. } \\
(2008)\end{array}$ & $\begin{array}{c}350 \text { adolescentes } \\
\text { (meninos e meninas), } \\
\text { não especifica camada } \\
\text { social }\end{array}$ & $\begin{array}{c}15 \text { a } 19 \\
\text { anos }\end{array}$ & $\begin{array}{l}\text { Qualitati } \\
\text { vo }\end{array}$ & $\begin{array}{l}\text { Oficinas lúdico- } \\
\text { pedagógicas }\end{array}$ & $\begin{array}{c}\text { Não há } \\
\text { descrição }\end{array}$ \\
\hline $\begin{array}{l}\text { MOREIRA et al. } \\
(2008)\end{array}$ & $\begin{array}{c}12 \text { adolescentes } \\
\text { grávidas, de camadas } \\
\text { populares }\end{array}$ & Não diz & $\begin{array}{l}\text { Qualitati } \\
\text { vo }\end{array}$ & $\begin{array}{c}\text { Diário de campo } \\
\text { e entrevista } \\
\text { aberta }\end{array}$ & $\begin{array}{c}\text { Agrupamento } \\
\text { em categorias } \\
\text { temáticas }\end{array}$ \\
\hline $\begin{array}{c}\text { FLORES; SULLCA; } \\
\text { SCHIRMER } \\
\text { (2006) }\end{array}$ & $\begin{array}{c}472 \text { adolescentes } \\
\text { grávidas e não- } \\
\text { grávidas, de camadas } \\
\text { populares }\end{array}$ & $\begin{array}{c}10 \text { a } 19 \\
\text { anos }\end{array}$ & $\begin{array}{l}\text { Quantita } \\
\text { tivo }\end{array}$ & $\begin{array}{l}\text { Entrevista e } \\
\text { formulário }\end{array}$ & $\begin{array}{c}\text { Análise } \\
\text { descritiva dos } \\
\text { dados SPSS }\end{array}$ \\
\hline
\end{tabular}


Naiana Dapieve Patias, Marília Reginato Gabriel, Ana Cristina Garcia Dias A família como um dos fatores de risco e de proteção nas situações de gestação e maternidade na adolescência

\begin{tabular}{|c|c|c|c|c|c|}
\hline $\begin{array}{c}\text { SILVA; TONETE } \\
(2006)\end{array}$ & $\begin{array}{c}9 \text { familiares de } \\
\text { adolescentes grávidas } \\
\text { (mãe, sogra, tia, irmã } \\
\text { e avó), de camadas } \\
\text { populares }\end{array}$ & $\begin{array}{c}19 \text { a } 58 \\
\text { anos }\end{array}$ & $\begin{array}{l}\text { Qualitati } \\
\text { vo }\end{array}$ & $\begin{array}{l}\text { Entrevista semi- } \\
\text { estruturada }\end{array}$ & $\begin{array}{l}\text { Método } \\
\text { elaborado por } \\
\text { Lefèvre e col. }\end{array}$ \\
\hline $\begin{array}{l}\text { GODINHO et al. } \\
(2000)\end{array}$ & $\begin{array}{l}20 \text { adolescentes } \\
\text { puérperas, de } \\
\text { camadas populares }\end{array}$ & $\begin{array}{c}\text { Idade } \\
\text { igual ou } \\
\text { inferior a } \\
19 \text { anos }\end{array}$ & $\begin{array}{l}\text { Qualitati } \\
\text { vo }\end{array}$ & $\begin{array}{l}\text { Entrevista semi- } \\
\text { estruturada }\end{array}$ & $\begin{array}{l}\text { Análise de } \\
\text { conteúdo }\end{array}$ \\
\hline $\begin{array}{l}\text { MONTEIRO et al. } \\
(2007)\end{array}$ & $\begin{array}{l}15 \text { adolescentes } \\
\text { puérperas, de } \\
\text { camadas populares }\end{array}$ & $\begin{array}{c}17 \text { a } 19 \\
\text { anos }\end{array}$ & $\begin{array}{l}\text { Qualitati } \\
\text { vo }\end{array}$ & $\begin{array}{l}\text { Entrevista semi- } \\
\text { estruturada }\end{array}$ & $\begin{array}{l}\text { Análise de } \\
\text { conteúdo }\end{array}$ \\
\hline $\begin{array}{c}\text { DIAS; GOMES } \\
(2000)\end{array}$ & $\begin{array}{c}12 \text { adolescentes } \\
\text { gestantes e uma } \\
\text { jovem mãe, camada } \\
\text { média baixa }\end{array}$ & $\begin{array}{c}12 \text { a } 19 \\
\text { anos }\end{array}$ & $\begin{array}{l}\text { Qualitati } \\
\text { vo }\end{array}$ & $\begin{array}{l}\text { Entrevista semi- } \\
\text { estruturada }\end{array}$ & $\begin{array}{c}\text { Análise } \\
\text { fenomenológica }\end{array}$ \\
\hline $\begin{array}{c}\text { GUIMARÃES; } \\
\text { WITTER (2007) }\end{array}$ & $\begin{array}{c}22 \text { adolescentes } \\
\text { grávidas, de camadas } \\
\text { populares }\end{array}$ & $\begin{array}{l}14 \text { a } 16 \\
\text { anos }\end{array}$ & $\begin{array}{l}\text { Quantita } \\
\text { tivo }\end{array}$ & $\begin{array}{l}\text { Questionário } \\
\text { com perguntas } \\
\text { abertas e } \\
\text { fechadas }\end{array}$ & $\begin{array}{c}\text { Análise } \\
\text { quantitativa }\end{array}$ \\
\hline $\begin{array}{l}\text { HOGA; BORGES; } \\
\text { ALVAREZ (2009) }\end{array}$ & $\begin{array}{c}19 \text { familiares (mãe, } \\
\text { pai e irmãs) de } \\
\text { adolescentes grávidas, } \\
\text { de camadas populares }\end{array}$ & $\begin{array}{c}23 \text { a } 56 \\
\text { anos }\end{array}$ & $\begin{array}{l}\text { Qualitati } \\
\text { vo }\end{array}$ & Entrevista & $\begin{array}{l}\text { Análise da } \\
\text { narrativa }\end{array}$ \\
\hline $\begin{array}{c}\text { ARCANJ O; DE } \\
\text { OLIVEIRA; } \\
\text { BEZERRA (2007) }\end{array}$ & $\begin{array}{c}40 \text { adolescentes } \\
\text { grávidas, de camadas } \\
\text { populares }\end{array}$ & $\begin{array}{c}14 \text { a } 19 \\
\text { anos }\end{array}$ & $\begin{array}{l}\text { Quantita } \\
\text { tivo }\end{array}$ & Questionário & $\begin{array}{l}\text { Análise } \\
\text { estatística }\end{array}$ \\
\hline HOGA (2008) & $\begin{array}{l}21 \text { mães adolescentes, } \\
\text { de camadas populares }\end{array}$ & $\begin{array}{c}14 \text { a } 18 \\
\text { anos }\end{array}$ & $\begin{array}{l}\text { Qualitati } \\
\text { vo }\end{array}$ & Entrevista & $\begin{array}{l}\text { Análise de } \\
\text { narrativa }\end{array}$ \\
\hline $\begin{array}{l}\text { LI MA et al. } \\
(2004)\end{array}$ & $\begin{array}{c}19 \text { adolescentes } \\
\text { grávidas e } 14 \\
\text { familiares, de camadas } \\
\text { populares }\end{array}$ & $\begin{array}{l}10 \text { a } 19 \\
\text { anos. }\end{array}$ & $\begin{array}{l}\text { Qualitati } \\
\text { vo }\end{array}$ & $\begin{array}{c}\text { Questionários e } \\
\text { entrevistas } \\
\text { abertas }\end{array}$ & $\begin{array}{l}\text { Análise de } \\
\text { conteúdo } \\
\text { quantitativa }\end{array}$ \\
\hline $\begin{array}{c}\text { SABROZA et al. } \\
(2001)\end{array}$ & $\begin{array}{c}1228 \text { puérperas, de } \\
\text { camadas populares e } \\
\text { médias }\end{array}$ & $\begin{array}{c}12 \text { a } 19 \\
\text { anos }\end{array}$ & $\begin{array}{l}\text { Quantita } \\
\text { tivo }\end{array}$ & Questionário & $\begin{array}{l}\text { Análise } \\
\text { estatística }\end{array}$ \\
\hline $\begin{array}{l}\text { XIMENES NETO; } \\
\text { DIAS; ROCHA; } \\
\text { CUNHA (2007) }\end{array}$ & $\begin{array}{c}216 \text { adolescentes } \\
\text { grávidas, de camadas } \\
\text { populares }\end{array}$ & $\begin{array}{c}12 \text { a } 19 \\
\text { anos }\end{array}$ & $\begin{array}{l}\text { Quantita } \\
\text { tivo }\end{array}$ & Questionário & $\begin{array}{c}\text { Análise } \\
\text { quantitativa }\end{array}$ \\
\hline $\begin{array}{c}\text { SABROZA; LEAL; } \\
\text { SOUZA; GAMA } \\
(2004)\end{array}$ & $\begin{array}{l}1228 \text { puérperas, de } \\
\text { camadas populares e } \\
\text { médias }\end{array}$ & $\begin{array}{c}12 \text { a } 19 \\
\text { anos }\end{array}$ & $\begin{array}{l}\text { Quantita } \\
\text { tivo }\end{array}$ & Questionário & $\begin{array}{c}\text { Análise } \\
\text { quantitativa }\end{array}$ \\
\hline $\begin{array}{c}\text { ALMEIDA; HARDY } \\
(2007)\end{array}$ & $\begin{array}{l}13 \text { pais adolescentes, } \\
\text { de camadas populares }\end{array}$ & $\begin{array}{c}12 \text { a } 19 \\
\text { anos }\end{array}$ & $\begin{array}{l}\text { Qualitati } \\
\text { vo }\end{array}$ & Entrevista & $\begin{array}{c}\text { Análise temática } \\
\text { de conteúdo }\end{array}$ \\
\hline $\begin{array}{c}\text { MACHADO; } \\
\text { SAITO; } \\
\text { SZARFARC (2007) }\end{array}$ & $\begin{array}{l}81 \text { adolescentes mães, } \\
\text { de camadas populares }\end{array}$ & $\begin{array}{l}\text { Menores } \\
\text { de } 19 \\
\text { anos }\end{array}$ & $\begin{array}{l}\text { Quantita } \\
\text { tivo }\end{array}$ & Entrevista & $\begin{array}{c}\text { Análise } \\
\text { quantitativa }\end{array}$ \\
\hline
\end{tabular}

Durante a etapa de leitura analítica na qual foram examinados dezenove artigos em sua integra, buscou-se, além da identificação dos elementos anteriormente apresentados no quadro, analisar esse corpus de dados a partir de duas grandes categorias temáticas construídas a priori, conforme os objetivos do estudo: fatores de risco 
e fatores de proteção na família associados às situações de gestação e maternidade durante a adolescência. Após a divisão do material pertencente aos fatores de risco e proteção, os resultados e conclusões dos 19 estudos analisados foram submetidos a uma nova análise de conteúdo temática, buscando identificar subcategorias descritivas dos fatores de risco e proteção. Por fim, destaca-se ainda que alguns artigos citados pelos autores dos 19 estudos analisados podem ter sido utilizados na descrição dos resultados. Esses estudos foram buscados toda vez que alguma ideia presente nos trabalhos analisados referente aos objetivos do trabalho, precisava ser melhor detalhada.

\section{Resultados e Discussão}

\subsection{Fatores de risco}

Nesta categoria serão discutidos aspectos relativos ao risco no contexto familiar, tanto no que diz respeito a fatores de risco anteriores a gestação, como durante e após a gestação da adolescente. As subcategorias são: dificuldades no relacionamento familiar, repetição da história familiar de gravidez adolescente e gestação sucessiva, falta ou inadequação da orientação sexual, escassez ou ausência de apoio familiar recebido, presença de violência e crenças e valores sobre a parentalidade.

Dificuldades no relacionamento familiar: Esta subcategoria ilustra os conteúdos dos artigos que se referem às dificuldades no relacionamento familiar presentes antes, durante e após a situação de gravidez adolescente. Os pais podem sofrer dificuldades com os filhos no período da adolescência, principalmente por não saber como lidar com a necessidade do jovem ser autônomo e, ao mesmo tempo, ser supervisionado e dependente do contexto familiar. De modo geral, os familiares não conhecem, não respeitam e/ou não possuem condições satisfatórias para prover as necessidades apresentadas pelos adolescentes (HOGA; BORGES; REBERTE, 2010), sendo observados conflitos entre pais e filhos, principalmente no que se refere à sexualidade (SOARES; AMARAL; SILVA; SILVA, 2008). Os genitores podem demonstrar ambiguidades em suas práticas, ao exercer o controle e/ou dar autonomia ao jovem, sendo que estas dificuldades acarretariam limitações nos diálogos estabelecidos entre pais e filhos, durante a adolescência. Os extremos de flexibilidade e de rigidez dos pais com os filhos são apontados como um dos possíveis fatores causais associados à situação de gravidez adolescente (HOGA et al. 2010). 
Além dos conflitos que envolvem a família como um todo, os estudos demonstram que os adolescentes possuem maiores dificuldades de relacionamento com a figura paterna (PERSONA; SHIMO; TARALLO, 2004; MOREIRA; VIANA; QUEIROZ; JORGE, 2008; SOARES et al. 2008). O pai é considerado o membro da família mais distante dos filhos, isso pode fazer com que os adolescentes temam as suas reações em relação ao exercício da sexualidade ou mesmo frente à ocorrência da situação de gravidez. Percebe-se que o temor da reação paterna à gravidez e descoberta do exercício da sexualidade é maior, sendo este frequentemente considerado uma pessoa agressiva e ignorante (MOREIRA; VIANA; QUEIROZ; JORGE, 2008; SOARES et al. 2008).

Repetição da história familiar de gravidez adolescente e gestação sucessiva: As pesquisas que constam nesta subcategoria dizem respeito à repetição da gravidez adolescente nas gerações da família, indicando a repetição da gravidez na adolescência entre diferentes gerações (transgeracionalidade) ou em uma mesma geração (situações de gestações sucessivas, ou de irmão(ã)s que passam por essa experiência durante a adolescência).

Há pesquisas que relatam que os filhos tendem a repetir a história reprodutiva de sua família - mães, irmãs, tias e primas ou de pessoas próximas - vizinhas (DIAS; GOMES, 2000; FLORES; SULLCA; CHIRMER, 2006; MOREIRA et al., 2008; PERSONA et al., 2004). Um estudo realizado por Flores, Sullca e Schirmer (2006) demonstra que as mães da maioria das adolescentes grávidas também tiveram gravidez na adolescência. Esse fator foi apontado como estando associado ao uso de violência física e psicológica durante a adolescência dos filhos como meio de prevenir o exercício da sexualidade precoce ou mesmo da situação de gravidez.

Silva e Tonete (2006), por sua vez, observam que a gravidez na adolescência é representada como um problema pelos familiares, que ancoram suas percepções nas suas próprias experiências com o fenômeno. Assim, esses autores encontraram que as avós - mães das adolescentes - indicam que não gostariam que suas filhas e netas se deparassem com as mesmas dificuldades que elas enfrentaram ao passar por essa experiência. Essas avós descrevem dificuldades econômicas, maior dependência da família de origem e dificuldades de inserção no mercado de trabalho, em função de uma menor escolarização.

O fenômeno das gestações sucessivas durante a adolescência é outro importante fator a ser considerado nas questões geracionais familiares (ROSA; REIS; TANAKA, 2007). De fato, tem-se observado que algumas adolescentes acabam tendo mais de um filho durante a adolescência, sendo possível encontrar uma segunda, terceira ou até quarta gestação antes dos 19 anos, a maioria sem ter planejado 
(PERSONA; SHIMO; ROSA; REIS; TANAKA, 2007; TARALLO, 2004). Essa repetição da gravidez entre adolescentes pode levar à desorganização familiar, abandono escolar, afastamento social e do mercado de trabalho, além de dificuldades emocionais (PERSONA; SHIMO; TARALLO, 2004).

Falta ou inadequação da orientação sexual: essa subcategoria congrega as pesquisas que indicam que a orientação sobre sexualidade e métodos contraceptivos é precária durante a adolescência.

Godinho, Shelp, Parada e Bertoncello (2000) observam que a família não é uma fonte frequentemente citada, no que se refere à questão da orientação sobre sexualidade. Muitas vezes, os próprios pais não obtiveram dos seus pais nenhuma orientação a respeito da sexualidade e contracepção e, portanto, possuem dificuldades de orientar seus filhos sobre o tema. Inclusive, algumas famílias não chegam a abordar esse tema com os filhos (HOGA; BORGES; ALVAREZ, 2009).

Mesmo quando a relação e a convivência familiar são harmoniosas, com a presença de diálogo e respeito, conversas sobre sexualidade e orientações sobre contracepção, autocuidado e gravidez na adolescência podem não ocorrer (ARCANJ O; DE OLIVEIRA; BEZERRA, 2007; MONTEIRO; COSTA; NASCIMENTO; AGUIAR, 2007). Desta forma, o fato de não existir conflito, não quer dizer que os assuntos sejam abordados e que inexistam problemas de comunicação. Questões culturais, vergonha e preconceito influenciam na possibilidade dos pais e de outros adultos conversarem com os jovens sobre sexualidade e contracepção, em especial, com as meninas (ARCANJO; DE OLIVEIRA; BEZERRA, 2007; MOREIRA; VIANA; QUEIROZ; JORGE, 2008).

De fato, no estudo de Dias e Gomes (2000) é apontado que existem barreiras comunicativas tanto por parte dos pais dos adolescentes como dos próprios jovens. As mães parecem negar a atividade sexual das filhas e estas, por sua vez, podem não se sentir a vontade para conversar sobre suas vidas sexuais com os pais. A ineficiência das fontes de orientação sexual e as dificuldades de compreensão sobre o assunto apresentado pelas jovens seriam provenientes de contradições nas informações recebidas.

A orientação sexual a adolescentes é complexa e possui uma variedade de motivações psicológicas, sociais e afetivas que concorrem para o desenvolvimento e efetivação ou não dessa orientação. Estudos demonstram que as conversas nesse âmbito não são efetivas, pois repetidamente são permeadas de "reticências, advertências e reprimendas". As orientações dos pais buscam frequentemente moldar o comportamento das filhas segundo uma lógica de preservação da moral, não as preparando efetivamente para 
- exercício de uma vida sexual segura (ARCANJO; DE OLIVEIRA; BEZERRA, 2007; DIAS; GOMES, 2000). O despreparo dos pais para lidar com assuntos e situações referentes à sexualidade é explicado também pelo fato dos mesmos não possuírem um modelo internalizado para efetuar essas conversar com os filhos, uma vez que os mesmos provavelmente não vivenciaram essa experiência com seus próprios pais (SOARES; AMARAL; SILVA; SILVA, 2008).

Essas dificuldades apresentadas pela família geralmente fazem com que a escola se torne uma fonte de informações sobre métodos contraceptivos e sexualidade. Guimarães e Witter (2007) indicaram que $55 \%$ das adolescentes buscavam informações na escola sobre sexualidade e contraceptivos. Contudo, Dias e Gomes (2000) apontaram a necessidade de avaliar a qualidade e a quantidade da informação prestada, além dos significados produzidos pelas diferentes fontes de informação sobre o tema. Os autores constataram que a comunicação se torna ineficaz e comprometida quando há falta de confiança no interlocutor, quando as informações são fragmentadas ou quando as mesmas estão comprometidas, pois estão permeadas de valores não aceitos pelo adolescente.

Observa-se então que as informações sobre sexualidade e contraceptivos podem estar ausentes ou serem insuficientes, em função de falhas na comunicação presente tanto no contexto familiar como em outros contextos (ARCANJO; DE OLIVEIRA; BEZERRA; 2007; DIAS; GOMES, 2000; MOREIRA; VIANA; QUEIROZ; JORGE, 2008; SILVA; TONETE, 2006). As informações sobre esses temas, de maneira geral, são obtidas por um número reduzido de adolescentes. Arcanjo, De Oliveira e Bezerra (2007), por exemplo, demonstram que $30 \%$ das adolescentes por eles entrevistadas jamais tiveram qualquer informação a respeito de sexualidade, o que indica dificuldades na comunicação sobre o assunto no contexto familiar.

Escassez ou ausência de apoio familiar recebido: a negação do apoio da família pela adolescente é referido pelas pesquisas, nesta subcategoria.

A gravidez na adolescência geralmente envolve renúncias, inclusive da perda de proteção e confiabilidade da família. De fato, algumas famílias não aceitam a situação da gravidez na adolescência. As famílias que não aceitam a gravidez, geralmente, são aquelas de camadas médias, que possuem outros projetos para seus filhos, relacionados à maior escolarização e profissionalização (MOREIRA et al. 2008). Nas camadas populares também pode haver uma não aceitação, que geralmente ocorre nos períodos iniciais do recebimento da notícia de gestação. Nesses contextos, a reação inicial dos pais é frequentemente de desgosto, rejeição e tristeza, contudo a atitude tende a mudar com o nascimento do bebê (LIMA et al., 2004). 
A reação negativa da família também pode ser sentida através da falta de apoio dos pais, expulsão ou agressão física. Essas reações podem fazer com que a adolescente considere o aborto, adoção e, até mesmo, o suicídio como alternativas para dar fim a essa situação difícil (MOREIRA et al., 2008).

As idealizações da adolescente (como ser independente dos pais, sair de casa, prender o namorado) se chocam com a realidade, quando a menina revela a gravidez aos pais e ao companheiro (MOREIRA et al., 2008). Esta pode experimentar o sentimento de abandono ou ter que realizar uma mudança radical em suas rotinas (por exemplo, sair de casa, ter que trabalhar) e projetos futuros (MOREIRA et al., 2008). Observa-se que mesmo em situações nas quais existe a expectativa de que a família e o pai do bebê apóiem a gravidez, as próprias adolescentes tratam à gestação como um problema só delas. Isso provavelmente se encontra associado às questões de gênero, que ainda apontam para a mulher como a principal à responsabilidade pela reprodução e criação dos filhos (GODINHO et al. 2000).

O apoio familiar torna-se mais evidente quanto mais nova for a adolescente, pois esta geralmente possui uma relação instável com o pai do bebê, sendo que a gravidez gera uma maior dependência da menina de seus pais (GODINHO et al. 2000). A dependência que se torna mais significativa para as adolescentes é a financeira, pois as jovens ficam impossibilitadas de trabalhar ou investir em suas carreiras em função dos cuidados com o bebê (HOGA, 2008).

Reações na família advindos da gravidez na adolescência: Nesta subcategoria, as pesquisas apresentam como a gravidez da adolescente repercutiu na família.

Monteiro, Costa, Nascimento e Aguiar (2007) consideram que a adolescente vive uma relação de normalidade e de afeto com sua família até o momento em que revela sua gravidez, a partir disso instaura-se o conflito e as cobranças realizadas pelos familiares. As cobranças referem-se, principalmente, ao descuido ou não uso de métodos contraceptivos pela adolescente, pois a maioria das jovens revela que suas mães as haviam alertado sobre a possibilidade de gestação (MONTEIRO et al. 2007). No entanto, destaca-se que, muitas vezes, esse alerta é dado de forma autoritária, o que não facilita o desenvolvimento de uma comunicação eficiente que poderia facilitar a adoção de um comportamento contraceptivo adequado (SILVA; TONETE, 2006).

De acordo com Sabroza et al. (2004), as reações negativas a gestação por parte da família e do pai do bebê são mais evidentes entre as mais jovens sem união consensual, pois espera-se que a gravidez adolescente aconteça, ao menos, em um relacionamento estável. Contudo, essa reação negativa inicial tende a melhorar com o passar do tempo, em função da necessidade de apoio vivida pelas 
adolescentes e pela construção de expectativas em relação ao futuro bebê (LEVANDOWSKI; PICCININI; LOPES; 2008; PERSONA et al., 2004; SABROZA; LEAL; GAMA; DA COSTA, 2004).

Há também descrições de famílias de adolescentes grávidas que se conformam com a gestação. No entanto, esse sentimento está associado a um discurso de impotência dos pais frente ao fenômeno, que descreve certa familiaridade com a situação, seja por vivências familiares ou da comunidade, na qual os indivíduos se encontram inseridos (SILVA; TONETE, 2006). Aqui observa-se certa naturalização e resignação com essa situação, que pode ser percebida como algo dado. Nesse sentido, percebe-se que alguns pais podem não se preocupar em conversar com os filhos a respeito da adoção de medidas contraceptivas, pois podem acreditar que as adolescentes são predestinadas a serem mães nesse período de vida. Esse tipo de reação pode ser mais observado em camadas menos favorecidas socioeconomicamente, nas quais as expectativas a respeito da escolaridade podem ser menores (SILVA; TONETE, 2006). Além disso, é comum observar que muitas adolescentes grávidas são filhas de mães que gestaram na adolescência, ou são irmãs de mães adolescentes (DIAS; GOMES, 2000; GODINHO, et al. 2000). Persona et al. (2004) indicam que tanto uma reação positiva como o apoio familiar à gestação pode ser considerado como um fator de vulnerabilidade para a repetição de gestação durante o período.

Ainda no que se refere ao impacto da gestação na família, Hoga, Borges e Alvarez (2009) consideram que a gravidez na adolescência traz como consequência, quase sempre, em ambas as classes econômicas, à destruição de planos e ao adiamento de sonhos, que levam a jovem a uma situação de (des) ajuste social, familiar e escolar. Essas mudanças bruscas podem levar a menina a um momento de crise, que dependendo do grau de ajuste da personalidade, a mesma pode sair fortalecida da situação ou caminhar para depressão ou tentativa de aborto (MONTEIRO; COSTA; NASCIMENTO; AGUIAR, 2007; XIMENES NETO et al, 2007).

Nesse momento inicial das reações dos membros da família ante a gravidez adolescente, os conflitos familiares relacionavam-se basicamente à desaprovação da gestação e ao receio de que a família pudesse se desestruturar, em função das modificações que são advindas do fenômeno. Dois exemplos de transformação são: a necessidade de readaptação de espaço físico e a necessidade de reajuste no orçamento familiar (MOREIRA et al. 2008).

Violência: esta subcategoria reúne artigos em que a violência física e psicológica está presente no cotidiano de adolescentes grávidas e não grávidas.

A violência intrafamiliar pode ser considerada como um dos fatores de risco para a ocorrência da gestação em adolescentes que ainda não são mães (HOGA, 2008; FLORES SULLCA; SCHIRMER, 2006). A 
violência não é considerada somente um risco prévio para a gravidez adolescente, como também é um fator de risco durante a gestação. A gestação pode ser um dos motivos para justificar a violência sofrida pelas adolescentes, principalmente no momento da revelação da gravidez. A notícia da gravidez pode gerar conflitos e violência que se manifesta tanto na forma de violência física (espancamento) como psicológica (xingamentos, ameaças de perda de afeto, agressões verbais, ridicularizações, humilhações, punições e cobranças). As adolescentes podem freqüentemente sentirem-se inferiorizadas, culpadas, discriminadas, humilhadas e punidas em seu próprio lar (MONTEIRO et al., 2007). Os artigos mencionam que a violência é um fator de risco que pode estar presente no contexto familiar, tanto antes da gestação e, portanto, contribuir para sua ocorrência (HOGA, 2008; FLORES SULLCA; SCHIRMER, 2006), quanto durante a gestação, vulnerabilizando a adolescente grávida e seu bebê (MONTEIRO et al., 2007).

Crenças e valores sobre a parentalidade: são congregados nesta subcategoria, os estudos que tratam das crenças e valores da família sobre maternidade e parentalidade.

A forma de criação que os pais oferecem aos filhos é influenciada, dentre outros fatores, pelas questões de gênero, ou seja, papéis prescritos socialmente para homens e mulheres (SOARES et al. 2008). A gravidez adolescente simboliza ainda, para alguns indivíduos, a comprovação da existência do relacionamento sexual antes do casamento. Este comportamento pode ser considerado inadequado especialmente para as mulheres, pois compromete a integridade moral das famílias. Esta situação pode ser interpretada como uma falha da família em prover uma educação adequada à filha (HOGA; BORGES; ALVAREZ, 2009).

De fato, esse evento é percebido como uma fraqueza da adolescente, que "caiu na conversa" dos homens, ou seja, não aderiu às orientações e valores familiares. Apesar da existência de mudanças nas regras sociais que regulam o contato e o namoro entre os adolescentes, estas não necessariamente foram acompanhadas de novos valores ou classificações morais sobre o comportamento feminino no âmbito da sexualidade. Neste sentido, tornar pública uma gravidez que ocorre na adolescência pode ser fonte de preocupação moral, não necessariamente de tristeza ou decepção familiar, porque se espera dos jovens que eles aproveitem à vida, estudem e se preparem para um futuro profissional e familiar (GROSSMAN, 2010).

As preocupações geradas por esses valores justificam a busca por providências imediatas, tomadas pelos membros da família, no sentido de regularizar a situação matrimonial de suas filhas, valorizado em camadas populares (HOGA et al. 2009). Nesse 
contexto, a maternidade e constituição da família se associam, e os membros da comunidade unem esforços para que os jovens possam constituir um novo núcleo familiar. Este, por sua vez, pode ser um dos únicos projetos de vida valorizados por adolescentes que vivem em um meio social desprovido de recursos materiais, financeiros e emocionais satisfatórios. A jovem pode ver na gravidez uma oportunidade para obtenção de afeto, reconhecimento e constituição de uma família e, com isto, acaba vulnerabilizada, especialmente, porque muitas dessas expectativas podem ser frustradas face à ocorrência do fenômeno (HOGA et al., 2010; XIMENES NETO et al., 2007).

A forma de inserção social da família também é um dos elementos sociais a ser associado a vulnerabilidades no campo da saúde sexual e reprodutiva dos adolescentes. De fato, dependendo do ambiente físico e social em que a família se encontra, essa pode ser mais ou menos vulnerável a certas condições ambientais que colaboram para a ocorrência da gestação na adolescência, como por exemplo: a exposição a drogas, a situações de violência, entre outras. Assim, dentre as razões para a gestação na adolescência, os problemas sociais e socioeconômicos da família podem contribuir para o desejo de ser mãe da adolescente e para construção da representação da maternidade como uma possibilidade concreta para sair de casa e construir uma família mais acolhedora (HOGA et al., 2010).

Para o menino adolescente, ser pai na adolescência relaciona-se ao conceito tradicional do que é ser homem, ou seja, ser viril e provedor. A gravidez na adolescência gera para o rapaz a necessidade de trabalho para o sustento da nova família. Contudo, esta atividade sofre uma re-significação nas classes populares (agora o menino passa a ser o provedor da própria família, como pai), uma vez que a inserção no mercado de trabalho, nesse contexto socioeconômico é, geralmente, anterior à ocorrência da gravidez adolescente (HOGA et al., 2010).

Considera-se que o risco para a gestação e maternidade na adolescência também estão associados às questões de gênero. De fato, nos moldes tradicionais, a menina deve ser mãe para ser mulher e ao homem cabe ser o provedor do lar. Homem é aquele que consegue demonstrar sua força através do trabalho. Essas concepções tradicionais colaboram para tornar os jovens mais vulneráveis a ocorrência de gestação nesse período de vida (ALMEIDA; HARDY, 2007).

\subsection{Fatores de proteção}

Nessa categoria serão discutidos aspectos relativos à proteção no contexto familiar, tanto no que diz respeito a fatores de proteção anteriores a gestação/maternidade, como durante a e após a 
gestação. As subcategorias apresentadas a seguir são: relacionamento familiar satisfatório, apoio recebido da família e mudanças positivas decorrentes da gravidez e maternidade adolescente.

Relacionamento familiar satisfatório: esta subcategoria é composta pelos elementos do relacionamento familiar, citados pelos artigos, que agem como fatores de proteção na situação de gravidez e maternidade adolescente.

O principal fator de proteção para o desenvolvimento saudável da adolescente, de acordo com Persona et al. (2004), é possuir um bom relacionamento com a mãe. Esse tipo de relacionamento pode abrir as portas para uma comunicação honesta entre mãe e filha sobre sexualidade e contracepção. Durante a gestação, e mesmo em momentos posteriores, um bom relacionamento com a mãe pode servir de apoio e proteção para eventuais dificuldades que possam emergir no período (PERSONA et al., 2004).

Apoio recebido da família: esta subcategoria trata do apoio fornecido pela família à adolescente gestante ou mãe.

Nas famílias que relaram que desejavam que a adolescente engravidasse, o impacto da notícia da gestação foi positivo, sendo acompanhado de grande alegria. De modo geral, essa situação ocorreu quando a jovem encontrava-se em um relacionamento estável com o pai da criança (SILVA; TONETE, 2006). A reação positiva à gestação associa-se ao fornecimento de amparo financeiro e apoio emocional familiar para a jovem gestante ou mãe (PERSONA et al., 2004). Este apoio, por sua vez, correlaciona-se a uma maior adesão às consultas pré-natais e às orientações dos profissionais de saúde (SABROZA et al. 2004).

Percebe-se que a intensidade e a forma como o apoio da família é fornecido variam de acordo com cada caso. Em alguns casos há toda uma mobilização dos membros da família para oferecer uma verdadeira rede de ajuda, sendo observados revezamentos entre os membros femininos da família (mãe, sogra, irmãs e adolescente) para o cuidado com a criança; as vezes, irmãos da jovem podem começar a trabalhar para ajudar no sustento do bebê. Esse apoio familiar correlaciona-se a adoção de novos modelos de comportamento por parte da adolescente, que assume definitivamente as responsabilidades presentes no mundo adulto, associadas à situação de maternidade. Ela mesma, após alguns meses do nascimento do bebê, procura fornecer o sustento e cuidado à criança, restringindo suas saídas noturnas. Além disso, a adolescente pode demonstrar o desejo de terminar os estudos para oferecer um futuro melhor ao filho (HOGA et al. 2009). O mesmo pode ocorrer com o companheiro da adolescente, que também é 
percebido como uma importante fonte de apoio no contexto familiar, uma vez que oferece tanto ajuda financeira como amor e afeto a adolescente e o bebê (GODINHO et al. 2000).

De fato, nas situações que a gravidez ocorre em um contexto de organização familiar sólida, as trajetórias das adolescentes, após o nascimento da criança, são marcadas por alianças e por suporte da rede social, que fornecem tanto apoio material como afetivo. Os vínculos afetivos e relacionais se reforçam entre os membros da família e as adolescentes, sendo ofertado tanto a adolescente como a criança um ambiente adequado ao desenvolvimento de ambas (HOGA et al. 2009).

As principais figuras de apoio são o pai e a mãe da adolescente (GODINHO et al., 2000). No entanto, outros familiares, tais como irmãs, tias e avós da jovem também ofereceram importante suporte (GODINHO et al., 2000; LIMA et al., 2004). Esse apoio se concretiza em forma de explicações em relação à maternidade, cuidado com o bebê, conselhos, ajuda afetiva e financeira e apoio moral (GODINHO et al., 2000).

O apoio da família pode ser vislumbrado, especialmente, através dos comportamentos e sentimentos de aceitação da gravidez da jovem, que podem ser percebidos tanto em momentos iniciais, logo após a revelação, ou mesmo, em momentos posteriores, quando o choque inicial da notícia foi superado. De qualquer forma, o apoio familiar reflete-se nos próprios cuidados da jovem com ela mesma e com o bebê (ARCANJ O et al., 2007, HOGA et al., 2010, LIMA et al., 2004).

Mudanças positivas decorrentes da gestação e maternidade adolescente: esta subcategoria trata das mudanças positivas descritas na literatura como fruto da gestação e maternidade adolescente.

Uma maior união da família pode ser observada como resultado da gestação, uma vez que os membros conjugam esforços para auxiliar a adolescente. A família preocupa-se tanto com o bem estar físico como emocional da adolescente, Ihe oferecendo cuidados durante a gravidez. Ela também auxilia na organização da jovem, especialmente quando elabora conjuntamente com ela os planos para o futuro, após o nascimento da criança. Além disso, alguns estudos indicam que a adolescente torna-se mais responsável após a gravidez, abandonando alguns comportamentos inadequados e desenvolvendo outros mais adequados, como preocupação com o trabalho e com o estudo (HOGA et al., 2010; MACHADO; SAITO; SZARFARC, 2007; SILVA; TONETE, 2006).

Observa-se que a gravidez e o nascimento da criança provocam forte impacto no cotidiano familiar, pois exigem mudanças no cotidiano, de espaço físico, hábitos de consumo, entre outras. Esses fenômenos geram modificações tanto na vida da adolescente como na vida 
familiar, cujos planos necessitaram ser adaptados a essa nova condição do membro da família (GUIMARÃES; WITTER, 2007).

\section{Considerações finais}

Neste artigo foram encontrados como prováveis fatores de risco anteriores à gestação na família: a ambiguidade dos pais na forma de se relacionarem com os filhos; as dificuldades no relacionamento das adolescentes com o pai (ou mesmo com a mãe); o histórico de gravidez adolescente na família; a boa impressão da experiência com a mãe adolescente, a ocorrência de gestações sucessivas durante a adolescência; as falhas na orientação sobre sexualidade e contracepção; as crenças e os valores tradicionais de família, as preocupações com a moral da filha e as representações que associam a gravidez e maternidade a ideia de oportunidade privilegiada na construção de um projeto de vida valorizado, face a escassez de outros projetos escolares e/ou profissionais valorizados viáveis. Já durante a gestação e após a mesma os familiares podem demonstrar reações negativas à gestação. A família de origem e o pai da criança podem não apoiar a jovem mãe, realizando acusações e maiores cobranças a adolescente, após a notícia da gravidez e nascimento do bebê. A família, após o nascimento da criança, cobra que a adolescente cuide da criança, abandonando atitudes consideradas não condizentes ao novo papel materno. Um fator que mostra a complexidade e o caráter processual presente na análise dos fatores de risco e proteção é a situação de gestações sucessivas. A literatura indica que quando a família realiza o apoio afetivo e financeiro da gestação e maternidade adolescente, a menina pode gestar novamente durante a adolescência, mesmo sem planejamento explicito prévio.

No que se refere aos fatores de proteção associados à ocorrência da gestação presentes no contexto familiar, destaca-se a importância da presença de bons níveis de comunicação entre pais e filho e de um ambiente familiar afetivo e continente ao adolescente. Um contexto com essas características possibilitaria que a adolescente postergue o inicio da vida sexual ou ingresse na mesma adotando medidas protetivas. Além disso, esse ambiente durante a gestação e maternidade adolescente possibilitaria uma vivencia mais positiva da gestação, melhor adesão ao acompanhamento pré-natal e o desenvolvimento da responsabilidade e cuidado com o filho.

A revisão da literatura nos permitiu observar que a maioria os estudos brasileiros publicados na última década foi realizado, em sua maioria, com adolescentes de camadas populares e poucos com camadas médias, sendo que quando esses ocorrem é porque realizam uma comparação entre esses dois estratos da população. Isso pode 
ser explicado por diferentes fatores: 1) talvez em camadas populares a gestação e maternidade adolescente seja mais frequente, especialmente porque são escassos os projetos que implicam em maiores níveis de escolarização e profissionalização; 2) os pesquisadores, em geral, coletam suas amostras em hospitais públicos ou unidades básicas de saúde que são, em geral, frequentados por estratos menos favorecidos da população; e 3) o acesso para o estudo das camadas médias é mais difícil do que as camadas populares. Isso pode ocorrer tanto em função de preconceito - a gestação e maternidade adolescente são percebidas como desvios de percurso, portanto, algo a ser escondido, como devido ao fato que nem sempre a gravidez é levada a termo (DADOORIAN, 2004; HEILBORN et al., 2002). Assim, ao analisarmos esses fenômenos é necessário se levar em consideração de que população se está falando, já que cada camada social apresente, algumas vezes, formas distintas de vivenciar e perceber esses fenômenos.

Por fim, destaca-se o caráter processual dos fatores de risco e proteção. Como já indicado, o apoio familiar conferido a gestante e mãe adolescente pode ser visto tanto como um fator de risco para ocorrência de uma próxima gestação (situação das gestações sucessivas) como um fator de proteção que permite a jovem superar problemas emergentes dessa nova situação de vida. Assim, retomase a idéia que é importante obter uma perspectiva processual na análise de risco e proteção, conforme proposto por Yunes e Szymansky (2003). Ao se trabalhar com a ideia do contexto familiar como um fator de risco e proteção, não pretende-se reduzir a compreensão dos fenômenos estudados a uma única variável - a família. Pretende-se sim, ampliar a compreensão desses fenômenos, incluindo-os na complexa rede de significados e de possibilidades, que juntos possibilitam a existência de uma maior ou menor vulnerabilidade das jovens às situações de maternidade e gestação na adolescência.

\section{Referências}

ALMEIDA, A. F. F.; HARDY E. Vulnerabilidade de gênero para paternidade em homens adolescentes. Revista de Saúde Pública, São Paulo, v. 41, n. 4, p. 565-72, 2007.

ALMEIDA, A. C. C. H.; CENTA, M. L. A. família e a educação sexual dos filhos: implicações para a enfermagem. Acta Paulista de Enfermagem, São Paulo, v. 22, n. 10, p. 71-76, 2009.

ARCANJ O, C. M.; DE OLIVEIRA, M. I. V.; BEZERRA, M. G. A. Gravidez em adolescentes de uma unidade municipal de saúde em Fortaleza - 
Ceará. Escola Anna Nery Revista de Enfermagem, Rio de Janeiro, v. 11 n. 3, p. 445-451, 2007.

BARDIN, L. Análise de Conteúdo. Lisboa: Edições 70, 1979.

BERTHOUD, C. M. Visitando a fase adolescente. In: CERVENY, C.; BERTHOUD, C. Visitando a família ao longo do ciclo vital. São Paulo: Casa do Psicólogo, 2002, p. 61- 84.

BRASIL. Estatuto da Criança e do Adolescente. Lei Federal $\mathrm{n}$ o 8.069, de 13 de Julho de 1990. Dispõe sobre o Estatuto da Criança e do Adolescente e dá outras providências.

CECCONELLO, A.; ANTONI, C.; KOLLER, S. Práticas educativas, estilos parentais e abuso físico no contexto familiar. Psicologia em Estudo, Maringá, n. 8 (Esp), p. 45-54, 2003.

CERQUEIRA-SANTOS, E.; PALUDO; S. S.; SCHIRÒ, E. D.; KOLLER, S. H. Gravidez na adolescência: análise contextual de risco e proteção.

Psicologia em Estudo, Maringá, v. 15, n. 1, p. 73-85, 2010.

CERVENY, C.; BERTHOUD, C. Visitando a família ao longo do ciclo vital. São Paulo: Casa do Psicólogo, 2002.

CHARLES, V.; BLUM, R. Core competencies and the prevention of high-risk sexual behavior. In: GUERRA, N.; BRADSHAW, C. (Eds). Core competencies to prevent problem behaviors and promote positive youth development. New Directions for child and adolescent development, 2008, p. 61-74.

COLL, C.; MARCHESI A.; PALACIOS, J. (Orgs). Desenvolvimento psicológico e educação. Porto Alegre: Artes Médicas, 1996, v. 3.

DADOORIAN, D. Gravidez na adolescência: um novo olhar. Psicologia: Ciência e Profissão, Brasília, v. 23, n. 1, p. 84-91, 2003.

DIAS, A. C. G. O adolescente e a saúde. In: Pavão, S. M. (org). Saúde no contexto interdisciplinar: por uma relação dialógica com crianças, adolescentes e adultos. Série Saúde, v. 3, Santa Maria: UNIFRA, 2006, p.17-87.

DIAS, A. C. G; GOMES, W. B. Conversas sobre sexualidade na família e gravidez na adolescência: a percepção dos pais. Estudos de Psicologia, Natal, v. 4, n. 1, p. 79-106, 1999.

- Conversas, em família, sobre sexualidade e gravidez na àdolescência: a percepção de jovens gestantes. Psicologia: Reflexão e Crítica, Porto Alegre, v. 13, n. 1, p. 109-125, 2000.

DIAS, A. C. G.; TEIXEIRA, M. A. P. Gravidez na adolescência: um olhar sobre um fenômeno complexo. Paidéia, Ribeirão Preto, v. 45, n. 20, p. 123-131, 2010.

ERIKSON, E. Adolescência: juventude e crise. Rio de Janeiro: Zahar, 1976.

FLORES SULLCA, T.; SCHIRMER J. Violência intrafamiliar na adolescência na cidade de Puno - Peru. Revista Latino-americana de Enfermagem, Ribeirão Preto, v. 14, n. 4, p. 578-85, 2006. 
GIL, A. C. Métodos e técnicas de pesquisa social. 5 ed. 7a reimpressão. São Paulo: Atlas, 2006.

GODINHO, R. A.; SHELP, J. R. B.; PARADA, C. M. G. L.; BERTONCELLO, N. M. F. Adolescentes e grávidas: onde buscam apoio? Revista Latino-americana de Enfermagem, Ribeirão Preto, v. 8, n. 2, p. 25-32, 2000.

GOMIDE, P. I.; MILLAN D.C; BOARON M.; RASQUIM S.; CZECZKO N. G; RIBAS C. P. Práticas parentais educativas e gravidez na adolescência. Revista Médica, Paraná, v. 63, n. 2, p. 1-9, 2005.

GUIMARÃES, E. A.; WITTER, G. P. Gravidez na adolescência: conhecimentos e prevenção entre jovens. Boletim da Academia Paulista de Psicologia, São Paulo, v. 27, n. 2, p. 167-180, 2007. GRANDESSO, M. Sobre a reconstrução do significado: uma análise epistemológica e hermenêutica da prática clínica. São Paulo: Casa do Psicólogo, 2000.

GROSSMAN, E. A construção do conceito de adolescência no Ocidente. Revista Saúde \& Adolescência, Rio de Janeiro, v. 7, n. 3, p. 47-51, 2010.

HALPERN-FELSHER, B. L.; KROPP, R. Y.; BOYER, C. B.; TSCHANN, J.M.; ELLEN, J. M. Adolescents self-efficacy to communicate about sex: its role in condom attitudes commitment and use. Adolescence, California, v. 39, n. 155, p. 443, 2004.

HEILBORN, M. L.; SALEM, T.; RODHEN, F.; BRANDÃO, E.; KNAUTH, D.; VÍCTORA, C.; AQUINO, E.; McCALLUM, C.; BOZON, M. Aproximações socioantropológicas sobre a gravidez na adolescência. Horizontes Antropológicos, Porto Alegre, v. 8, n 17, p.13-45, 2002.

HOGA, L. A. K. Maternidade na adolescência em uma comunidade de baixa renda: experiências reveladas pela história oral. Revista Latino-Americana de Enfermagem, Ribeirão Preto, v. 16, n. 2, p. 280-286, 2008.

HOGA L. A. K.; BORGES A.; ALVAREZ R. Gravidez na adolescência: valores e reações dos membros da família. Acta Paulista de Enfermagem, São Paulo, v. 22, n. 6, p. 779-785, 2009.

HOGA, L. A. K., BORGES, A. L. V.; REBERTE,L. M. Razões e reflexos da gravidez na adolescência: narrativas dos membros da família. Escola Anna Nery Revista de Enfermagem, Rio de Janeiro, v. 14, n. 1, p. 151-157, 2010.

HUTZ, C. (Org). Situações de risco e vulnerabilidade na infância e adolescência: aspectos teóricos e estratégias de intervenção. São Paulo: Casa do Psicólogo, 2002.

HUTZ, C. Violência e risco na infância e adolescência: pesquisa e intervenção. São Paulo, Casa do Psicólogo, 2005.

KNOBEL, M. Síndrome da adolescência normal. In: ABERASTURY, A.; KNOBEL, M. Adolescência normal: um enfoque psicanalítico. Porto Alegre, RS: Artes Médicas, 1981. p.63-71. 
KOTCHICK, B.; SHAFFER,A.; FOREHAND, R. Adolescent sexual riskbehavior: a multi-system perspective. Clinical Psychology Review, v. 21, n. 4, p. 493-519, 2001.

LAVILLE C.; DIONNE, J. A construção do saber: manual de metodologia da pesquisa em ciências humanas. Belo Horizonte: Editora UFMG, 1999.

LEVANDOWSKI, D.; PICCININI, C.; LOPES, R. (2008). Maternidade Adolescente. Estudos de Psicologia, Campinas, v. 25, n. 2, p. 251263, 2008.

LIMA C. T. B.; FELICIANO K. V. O.; CARVALHO M. F. S.; SOUZA A. P. P.; MENABÓ J. B. C.; RAMOS L. S.; CASSUNDÉ L. F.; KOVACS M. H. Percepções e práticas de adolescentes grávidas e de familiares em relação à gestação. Revista Brasileira de Saúde Materno-infantil, Recife, v. 4, n. 1, p. 71-83, 2004.

LOPES, A. L. M.; FRACOLLI, L. A. Revisão sistemática de literatura e metasíntese qualitativa: Considerações sobre sua aplicação na pesquisa em enfermagem. Revista Texto \& Contexto Enfermagem, Florianópolis, v. 17, n. 4, p-771-778, 2008.

LUSTER T.; SMALL, S. Factors associated with sexual risk-taking behaviors among adolescents. Journal of Marriage and the Family, Michigan, v. 56, 622-632, 1994.

MACHADO N. O.; SAITO M. I.; SZARFARC S. C. Características sóciodemográficas e reprodutivas de adolescentes atendidas no pós-parto no Instituto da Criança da Universidade de São Paulo. Revista Brasileira de Crescimento e Desenvolvimento Humano, São Paulo, v. 17, n. 3, p. 1-7, 2007.

MARIN A., LEVANDOWSKI D. Práticas educativas no contexto da maternidade adolescente: breve revisão de literatura. Interação em Psicologia, Curitiba, v. 12, n. 1, p. 107-113, 2008.

MONTEIRO, C., COSTAN, N. P.; AGUIAR Y. (2007). A violência intrafamiliar contra adolescentes grávidas. Revista Brasileira de Enfermagem, Brasília, v. 60, n. 4, p. 373-376, 2007.

MORAIS, N. A.; KOLLER, S. Abordagem ecológica do desenvolvimento humano, psicologia positiva e resiliência: Ênfase na saúde. IN: KOLLER, S. (Ed.), Ecologia do desenvolvimento humano: Pesquisa e intervenções no Brasil. São Paulo: Casa do Psicólogo, 2004, p. 91-107.

MORAIS, N. A. Trajetórias de vida de crianças e adolescentes em situação de vulnerabilidade social: entre o risco e a proteção, 241f. Dissertação de mestrado em Psicologia nãopublicada, Universidade Federal do Rio Grande do Sul, Porto Alegre, 2009.

MOREIRA, T.; VIANA, D.; QUEIROZ, M.; JORGE, M. Conflitos vivenciados pelas adolescentes com a descoberta da gravidez. Revista Escola de Enfermagem USP, São Paulo, v. 42, n. 2, p. 312-320, 2008. 
PERSONA L.; SHIMO A.K.K.; TARALLO M.C. Perfil de adolescentes com repetição da gravidez atendidas num ambulatório de pré-natal. Revista Latino-Americana de Enfermagem, Ribeirão Preto, v. 12, n. 5, p.745-50, 2004.

PESCE, R. P.; ASSIS, S. G.; SANTOS, N.; OLIVEIRA, R. DE V. C. Risco e proteção: em busca de um equilíbrio promotor de resiliência. Psicologia: Teoria e Pesquisa, Brasília, v. 20, n. 2, p. 135-143, 2004.

POLETTO, M.; KOLLER, S. H. Contextos ecológicos: promotores de resiliência, fatores de risco e de proteção. Estudos de Psicologia, Campinas, v. 25, n. 3, p. 405-416, 2008.

PRETO, N. Transformações do sistema familiar na adolescência. In: B. CARTER \& M. MCGOLDRICK. As Mudanças no Ciclo de Vida Familiar: Uma estrutura para a terapia familiar. Porto Alegre: Artmed, 1995, 223-247.

SABROZA, A. R.; LEAL M. C.; GAMA, S. G.; DA COSTA, J. V. Perfil sócio-demográfico e psicossocial de puérperas adolescentes do Município do rio de Janeiro, Brasil - 1999-2001. Cadernos de Saúde Pública, Rio de Janeiro, v. 20, n. 1, p. 112-120, 2004.

SABROZA, A. R.; LEAL, M. C.; SOUZA J. R.; GAMA, S. G. Algumas repercussões emocionais negativas da gravidez precoce em adolescentes do Município do rio de Janeiro (1999-2001). Cadernos de Saúde Pública, Rio de Janeiro, v. 20, n. 1, p. 130-137, 2004.

SALVO, C. G. Práticas educativas parentais e comportamentos de proteção e risco à saúde em adolescentes. Tese de doutorado não-publicada, 235f. Universidade de São Paulo, São Paulo, 2010.

SCHENKER, M.; MINAYO, M. C. S. Fatores de risco e de proteção para o uso de drogas na adolescência. Ciências e Saúde Coletiva, Rio de Janeiro, v. 10, n. 3, p. 707-717, 2005.

SHAFFER, D. R. Psicologia do desenvolvimento: infância e adolescência. Cíntia Regina Pemberton Cancissu (Trad.) São Paulo: Pioneira, 2005.

SILVA, L.; TONETE, V. A gravidez na adolescência sob a perspectiva dos familiares: compartilhando projetos de vida e cuidado. Revista Latino-americana de Enfermagem, Ribeirão Preto, v. 14, n. 2, p. 199-206, 2006.

SOARES, S. M.; AMARAL, M. A.; SILVA, L. B.; SILVA, P. A. B. Oficinas sobre sexualidade na adolescência: revelando vozes, desvelando olhares de estudantes do ensino médio. Escola Anna Nery Revista de enfermagem, Rio de Janeiro, v. 12, n. 3, p. 485-491, 2008.

TAQUETTE, S.; VILHENA, M. Uma contribuição ao entendimento da iniciação sexual feminina na adolescência. Psicologia em Estudo, Maringá, v. 13, n. 1, p. 105-114, 2008.

TEIXEIRA, M. A. P.; DIAS, A. C. G. Quando termina a adolescência? Perspectiva, Erechim, v. 28, n. 102, p. 7-15, 2004. 
WEBER, L. (2007). Eduque com carinho: equilíbrio entre amor e limites. 2a Edição. Curitiba: Juruá, 2007.

WORLD HELATH ORGANIZATION. Adolescent health \& development. 2010. Disponível em: <http://www.searo.who.int/en/Section13/Section1245.htm>. Acesso em: 06 abr. 2010.

VILLELA, W. V.; DORETO, D. T. Sobre a experiência sexual dos jovens. Cadernos de Saúde Pública, Rio de Janeiro, v. 22, n. 11, p. 2467-2472, 2006.

YUNES, M., MIRANDA, A.; CUELLO, S. Um olhar ecológico para os riscos e as oportunidades de desenvolvimento de crianças e adolescentes institucionalizados. In: KOLLER, S. (Ed.). Ecologia do desenvolvimento humano: Pesquisa e intervenções no Brasil. São Paulo: Casa do Psicólogo, 2004, p. 197-218.

YUNES, M.; SZYMANSKI, H. Crenças, sentimentos e percepções acerca da noção de resiliência em profissionais da Saúde e Educação que atuam com famílias pobres. Psicologia da Educação, São Paulo, v. 17, p. 119-137, 2003.

XIMENES NETO, F.R; DIAS, M.S, ROCHA, J.; CUNHA, I. C. Gravidez na adolescência: motivos e percepções das adolescentes. Revista Brasileira de Enfermagem, Brasília, v. 60, n. 3, p. 279-285, 2007.

\section{Endereço para correspondência \\ Naiana Dapieve Patias}

Rua Silva Só, 280, apto 304, Bairro: Santa Cecília, CEP: 90610-270, Porto Alegre RS.

Endereço eletrônico: naipatias@hotmail.com

\section{Marília Reginato Gabriel}

Rua Silva Só, 280, apto 304, Bairro: Santa Cecília, Cep: 90610-270, Porto Alegre RS.

Endereço eletrônico: gabrielmarilia@yahoo.com.br

Ana Cristina Garcia Dias

Rua Floriano Peixoto, 1750, sala 308,Centro, Santa Maria, RS. Cep: 97015372

Endereço eletrônico: anacristinagarciadias@gmail.com

Recebido em: 30/05/2011

Reformulado em: 09/01/2012

Aceito para publicação em: 30/06/2012

Acompanhamento do processo editorial: Deise Mancebo

\section{Notas}

* Psicóloga, Mestre em Psicologia pela Universidade Federal de Santa Maria (UFSM) e doutoranda em Psicologia pela Universidade Federal do Rio Grande do Sul - (UFRGS).

**Psicóloga, Mestre em Psicologia pela Universidade Federal do Rio Grande do Sul, UFRGS e doutoranda pela mesma universidade.

***Psicóloga, Doutora em Psicologia pela USP, Docente do Programa de Pós Graduação em Psicologia da Universidade Federal de Santa Maria(UFSM)

${ }^{1}$ Nesse artigo refere-se a família enquanto sistema, de acordo com Cerveny e Berthoud (2002). Esses autores revelam que a família opera de acordo com certos 
princípios básicos e que evolui em seu desenvolvimento, de modo particular e complexo determinado por inúmeros fatores, internos e externos. Um dos princípios do sistema família é a circularidade, na qual as ações e comportamentos de um dos membros influenciam e são influenciados pelos comportamentos de todos os outros (GRANDESSO, 2000).

2 A gravidez na adolescência é considerada pela Organização Mundial da saúde (OMS, 2010) como aquela que ocorre entre os 10 e 19 anos de idade. Tem sido tradicionalmente caracterizada como um problema de saúde pública. De fato, a gravidez por si só propicia uma série de modificações biopsicossociais que, aliadas as transformações da própria adolescência, pode gerar uma série de dificuldades para a jovem e sua família (LEVANDOWSKI; PICCININI; LOPES, 2008; MARIN; LEVANDOWSKI, 2008). Do mesmo modo, a maternidade adolescente pode ser encarada como diferente de uma maternidade na adultez, sendo associada, muitas vezes, à incompetência e, até mesmo, negligência por parte da mãe adolescente para com os cuidados e educação do bebê (MARIN; LEVANDOWSKI, 2008). 